\title{
Ontologia e objetividade em Feuerbach e Marx
}

Vinícius Pereira Bezerra ${ }^{1}$

\section{Resumo:}

O presente trabalho busca rastrear em alguns escritos de L. Feuerbach os lineamentos de uma ontologia materialista do ser objetivo e seu papel correspondente e capital no pensamento de Marx. Ler em Marx uma obra de corte ontológico, à maneira de Lukács, e um tal movimento de apreensão do talhe materialista-ontológico em Feuerbach indica que este não apenas tem como traço uma antropologia filosófica, efetivamente enunciada em sua aguda crítica à religião, que seria então superada rumo a uma ontologia por Marx, mas que há já no autor d'A essência do cristianismo um primado ontológico do ser objetivo indelével, resguardado e aperfeiçoado por Marx em sua crítica a Feuerbach no que concerne às determinações presentes na relação entre natureza e sociedade. Neste esforço, a análise se concentra na leitura imanente de alguns escritos feuerbachianos produzidos sobretudo entre 1839 e 1843 a saber, Para a crítica da filosofia de Hegel (1839), A essência do cristianismo (1841), Necessidade de uma reforma da filosofia (1842), Teses provisórias para a reforma da filosofia (1842) e Princípios da filosofia do futuro (1843) - e de Marx, especialmente os Manuscritos econômico-filosóficos (1844). É possível notar no pensamento de Feuerbach um movimento pendular entre a asserção de uma percuciente objetividade materialista do ser e uma primazia assoberbada da consciência e da essência humana. Ambivalência que, ao final, põe enormes dificuldades à captura da objetividade em sua forma mais complexa de ser, o ser social.

Palavras-chave: ontologia; objetividade; Feuerbach; Marx.

\section{Ontology and objectivity in Feuerbach and Marx}

\begin{abstract}
:
The present assignment intends to trace in some of L. Feuerbach's writings the guidelines for a materialist ontology of an objective being and its correspondent role and capital on Marx's thoughts. To find in Marx a work with ontological section, the manner of Lukács, and such apprehension movement of ontological materialism cut in Feuerbach, indicates that this
\end{abstract}

1 Doutorando na Universidade Federal do Ceará (UFC) e professor do Instituto Federal do Maranhão. E-mail: vpbezerra@gmail.com. 
not only has traces of a philosophical anthropology, effectively announced in his sharp criticism of religion, which would then be overcome towards an ontology by Marx, but also there's already in The essence of Christianity's author some ontological primacy of the indelible objective being sheltered by Marx and improved by him, in his criticism of Feuerbach, as regards to the determinations present in the relationship between nature and society. In this effort, the analysis focus in immanent reading of some Feuerbachians writings created especially between 1839 and 1843, viz., Towards a critique of Hegel's philosophy (1839), The essence of Christianity (1841), The necessity of a reform of philosophy (1842), Provisional theses for the reformation of philosophy (1842) and Principles of the philosophy of the future (1843), and from Marx particularly Economic and philosophic manuscripts of 1844. It's possible observe in Feuerbach's thinking a swinging pendulum between either an assertion of an insightful materialist objectivity or a overwhelmed primacy of conscience and human essence, the type of ambivalence that, after all, places huge difficulties in the capture of the objectivity in his most complex form of be, the social being.

Key words: ontology; objectivity; Feuerbach; Marx.

\section{1- Introdução}

Em Para uma ontologia do ser social, colhemos de György Lukács (2012) uma posição decisiva acerca do pensamento de Marx, segundo a qual este teria instituído uma forma radicalmente nova de fazer filosofia e ciência, porquanto sua obra ser fundada e perpassada por um inaugural tratamento ontológico do ser em suas determinações categoriais mais complexas, ou seja, as determinações correspondentes ao período societário no qual o capital estabelece uma madura regência, a época contemporânea que transcorre desde a primeira metade do século XIX até os nossos dias².

Parte importante deste novo tratamento conferido por Marx ao estatuto do ser e suas formas cambiantes teria sido ter encontrado uma justa solução para a relação entre objetividade e subjetividade, entre ser e consciência, que até então tinha se enredado em impasses insolúveis na

2 Marx salienta que o modo de produção capitalista atinge sua maturidade em meados de 1824, quando da emergência da primeira crise econômica de superprodução. Este amadurecimento chega à sua realização mais efetiva na medida em que o proletariado passa a imiscuir-se na arena da luta de classes, acontecimento testemunhado pelas revoluções europeias de 1848, a primeira sublevação histórica daquele sujeito como classe para-si e também sua primeira grande derrota histórica para a burguesia. 
história da filosofia, visto que ora se exagerava em demasia um polo (o ser objetivo), ora o outro (a subjetividade, o pensamento, a razão), formando um quadro amiúde deformado do processo de entificação.

Ainda segundo o filósofo húngaro, na urdidura ontológica de Marx, “o primeiro e indispensável pressuposto" consiste em que “a ontologia do ser social pressupõe uma ontologia geral". Descuidar deste alicerce seria recair decerto "em permanente confusão entre a realidade objetiva e seu espelhamento imediato, que - considerado no plano ontológico - é sempre subjetivo" (LUKÁCS, 2012, p. 27).

Reputamos a Ludwig Feuerbach (1804-1872), todavia, o fato de ter instaurado de modo luminoso esse pressuposto tão caro ao desenvolvimento do pensamento de Marx. O que, a um só tempo, repõe em traço mais adequado o feito de cada um deles, a relação entre ambos e a correção materialista encontrada na história da ontologia que, principalmente em relação a Feuerbach, faz jus à grandeza do seu empreendimento, com frequência apenas reservado ao apagar das luzes do idealismo clássico alemão.

Longe de aventar que seja Feuerbach o primeiro materialista afinal, é amplamente sabido o longo percurso desde o materialismo antigo, passando pelo nominalismo e pelos modernos materialismos inglês e francês, até sua elaboração acabada nos termos do materialismo históricodialético, processo este concomitante à complexificação social e ao progresso da ciência - , o que é meritório destacar é que ele deitou raízes para a emergência de um novo materialismo, a partir de um fecundo solo preparado por Hegel. A nosso ver, dois aspectos-chave promanam da filosofia feuerbachiana, apesar de seus limitados desenvolvimentos posteriores ou mesmo desacertos analíticos, e são superados no seio do novo materialismo de Marx: o reconhecimento da radical prioridade do ser objetivo no compósito da realidade e da mundanidade e, nesta providência, a dação de uma linha materialista fundamental para a compreensão da subjetividade. É cioso observar que a noção de superação de ambos os aspectos em tela no interior do materialismo marxiano reclama o sentido já aclarado por Hegel, para quem a superação consigna a conservação.

Sobre o ambiente intelectual e político alemão dos anos 1840, com a ascensão de Frederico Guilherme IV ao poder soberano, quando então se assistia, no interior da decomposição da escola hegeliana, ao acirramento de posições entre os jovens hegelianos de esquerda e "[à] beataria ortodoxa e [à] reação feudal-absolutista” (ENGELS, s/d, p. 176), Engels asseverava que o aparecimento de A essência do cristianismo [Das Wesen des Christentums], em 1841, provocou grande agitação entre seus coetâneos. Entre as polêmicas gestadas pelos neo-hegelianos em seus debates com o 
sistema hegeliano e sua concepção de realidade, dizia ele, "essa obra pulverizou a contradição criada ao restaurar o materialismo em seu trono". E destacava, em sua ardente reminiscência, passados 47 anos:

Só tendo vivido, em si mesmo, a força libertadora desse livro, é que se pode imaginá-la. O entusiasmo foi geral - e momentaneamente todos nós nos transformamos em "feuerbachianos". Com que entusiasmo Marx saudou a nova concepção e até que ponto se deixou influenciar por ela apesar de todas as suas reservas críticas - pode ser visto em A sagrada família. (ENGELS, s/ d, p. 177, destaque nosso)

O próprio Marx, em missiva a Feuerbach, de 11 de agosto de 1844, comentou que os escritos deste, como Princípios da filosofia do futuro e A essência da fé, deram um "fundamento filosófico ao socialismo" (MARX, 1974, p. 179).

A considerar o triunfo da filosofia burguesa contemporânea que vai do neopositivismo ao pós-modernismo, toda ela angulada por um crasso subjetivismo, ou interpretações do pensamento de Marx que obnubilam aquele primeiro pressuposto ancorado em uma ontologia geral ${ }^{3}$, retomar os lineamentos de uma ontologia materialista do ser objetivo é exigência de primeira ordem no plano teorético da reabilitação de Marx.

Neste artigo, buscamos avançar no desenvolvimento aproximativo da apreensão marxiana do estatuto categorial como Daseinsformen ${ }^{4}$ mediante a sua confrontação com a fortuna crítica herdada de Feuerbach, dado o quão importante isso se revela no entendimento da díade objetividade-subjetividade e, por extensão, dos problemas que envolvem este par modal no que compete à análise das forças produtivas, estudo em curso em nível de doutoramento pelo autor.

\section{2 - Da centralidade do ser objetivo em Feuerbach}

O ser existe a partir de si e por si - o ser é só dado pelo ser. Ludwig Feuerbach

Sabe-se que o esforço teórico maior de Feuerbach foi proceder a um exame crítico contumaz da essência da religião e da teologia, expressem-se estas seja na forma do cristianismo ou das religiões pagãs, seja na forma da

\footnotetext{
3 Como se depreende, e.g., em Grespan: "Sem dúvida esta objeção [de Marx à 'forma mistificada' da dialética hegeliana] alude ao caráter hiperbólico da dialética de Hegel, que vê todo o real - natureza e espírito - como contraditório, enquanto para Marx só o é certo tipo de relação social historicamente constituída, a saber, o das sociedades de classe em geral e da capitalista em particular." (GRESPAN, 2002, pp. 29-30)

${ }^{4}$ Conforme diz Marx (2011, p. 59): "as categorias expressam formas de ser, determinações de existência [die Kategorien dahen Daseinsformen, Existenzbestimmungen]" (cf. também ALVES, 2013).
} 
filosofia especulativa que, segundo ele, apenas revestia sob um invólucro racional a essência da consciência teológica. Tudo isso a partir de um fundamento humanista que buscava revelar a antropologia como o segredo da teologia, conforme sentenciou na abertura das Teses provisórias para a reforma da filosofia (1842).

A essência do cristianismo (1841) tornou-se, nesse plano, sua obra mais conhecida, cujo sentido era apanhar na religião a duplicidade de sua essência, a saber, uma essência geral, que indica que o objeto e o conteúdo da religião cristã são inteiramente humanos, a própria essência humana objetivada; e uma essência peculiar, que consiste exatamente na falta de consciência sobre este fato, isto é, que a consciência religiosa e seus predicados são os próprios predicados da essência humana objetivados. No que tange ao traço peculiar, tem-se o movimento de objetivação [Vergegenständlichung] ${ }^{5}$ da própria essência humana, por meio do qual "O homem transporta primeiramente a sua essência para fora de si antes de encontrá-la dentro de si”, no qual "O homem objetivou-se [na religião], mas não reconheceu o objeto como sua essência”, desta maneira, "julga ela [a religião] que o seu objeto, o seu conteúdo é sobre-humano" (FEUERBACH, 1989a, p. 56). Esta essência peculiar, portanto, é deveras negativa e marcadamente teológica, revelando um conteúdo próprio da alienação humana6, pois "para enriquecer Deus o homem deve se tornar pobre, para que Deus seja tudo e o homem nada", ou, ainda, "O homem afirma em Deus o que ele nega em si mesmo" (FEUERBACH, 1989a, p. 68.).

Sua tese postula que a religião é uma alienação da essência humana, uma forma de consciência do que haveria de melhor no humano - a sua universalidade e infinitude - projetada para fora dele, separada dele e que exerce domínio sobre ele. O que implica dizer que a religião não tem uma essência própria, um fundamento metafísico, antinatural e inumano, representado, nesse caso, por Deus; pelo contrário, teria sua essência fundada no próprio homem. Por isso, a religião, enquanto objeto de escrutínio filosófico, coloca uma questão fundamental e antropológica: descobre o homem, o poder de sua consciência, sua universalidade.

5O emprego das categorias exteriorização, objetivação e alienação em nosso texto coteja preferencialmente a tradução de Entäusserung por exteriorização, Entfremdung por alienação e Vergegenständlichung por objetivação. Acompanhamos as opcões já adotadas em edições tais como Fernandes (1989) e Marx (2015).

6“É o que de fato afirma Feuerbach, em sua nova teoria da alienação, que denuncia no ser absoluto, ou seja, em Deus e no Espírito Absoluto da evolução intelectual hegeliana, a alienação da essência humana (...). Tomar o predicado pelo sujeito, o pensamento pelo ser, separá-los, e dar ao primeiro autonomia e dominância é, na crítica de Feuerbach, o segredo oculto do método hegeliano e da própria religião cristã. É esta a inversão do conceito de alienação hegeliana que ele propõe em A essência do cristianismo." (SAMPAIO; FREDERICO, 2006, p. 52) 
A antropologia patente de Feuerbach foi de tal modo realçada, entretanto, que se obscureceram os lineamentos materialistas que dão o substrato de sua filosofia ontologicamente interessada, pois, diz ele, "A filosofia é o conhecimento do que é. Pensar e conhecer as coisas e os seres como são - eis a lei suprema, a mais elevada tarefa da filosofia" (FEUERBACH, 1988, p. 26).

Gíl Martínez (2016), em seu amplo mapeamento da recepção da filosofia de Feuerbach, considera, entre os esforços de periodização de seu pensamento, aquele proposto por Xhaufflaire o mais consistente, na seguinte consecução de temário: Razão (1825-38), Antropologia (1839-43) e Sensualidade e Natureza (1844-72). O específico da filosofia feuerbachiana se encontraria nas noções de Sinnlichkeit (sensibilidade) e Leiblichkeit (corporeidade) como medidas de realidade e como fundamentos de cognoscibilidade e existência, além de uma antropologia orientada na relação recíproca do Eu e do Tu. O autor propõe o conceito de crítica como aquele que melhor se presta a princípio explicativo imanente de continuidade e evolução da filosofia de Feuerbach. Apesar da evidente relevância do conceito, causa espécie o seu silêncio sobre como a ontologia constitui um campo de interesse fundante no manejo feuerbachiano dos problemas, ou como o emprego ontológico da categoria ser por Feuerbach institui uma angulação íntima e distintiva na viragem materialista por ele promovida7.

Sustenta a expertise que 1839 demarca o início do segundo período da produção feuerbachiana, de marca antropológica e com o acento mais característico de sua filosofia sensualista, momento em que vem a lume o seu aberto confronto com a filosofia hegeliana. Debruçando-nos especialmente sobre os textos desta fase, nosso mote, no entanto, buscará evidenciar o cariz propriamente ontológico que baliza sua reflexão.

\subsection{A virada de 1839}

Para a crítica da filosofia de Hegel [Zur Kritik der Hegelschen Philosophie], texto produzido em 1839, representa a primeira obra de Feuerbach de caráter crítico dialético acerca estritamente da filosofia hegeliana. O ensejo de sua elaboração veio a partir do convite de Arnold Ruge, ainda em 1837, para que Feuerbach colaborasse nos Anais de Halle [Hallische J ahrbücher], dirigidos pelo primeiro. Dois textos resultaram de sua colaboração, ambos publicados em 1839: Sobre filosofia e cristianismo [Über Philosophie und Christentum] e Para a crítica da filosofia de Hegel. Em realidade, o segundo texto advém do pedido de Ruge para Feuerbach

7 "O conceito do ser, da existência é o conceito primevo, original, da verdade [Der Begriff des Seins, der Existenz ist der erste, ursprüngliche Begriff der Wahrheit]" (FEUERBACH, 1989a, p. 62). 
resenhar o livro Ideia e história da filosofia [Idee und Geschichte der Philosophie], de 1838, de Karl Theodor Bayrhoffer, o qual defende, como outros neo-hegelianos do período, a ideia de que a filosofia atingiu com Hegel sua realização absoluta, a realização da razão una e universal, do puro logos da filosofia moderna em seu acabamento (CHAGAS; REDYSON, 2012). No texto, ele era mencionado apenas como "um hegeliano" - "um espírito perspicaz, pensante e livre" - que "procurou demonstrar formalmente, e à sua maneira com fundamento, que a filosofia de Hegel é 'a realidade absoluta da ideia de filosofia'” (FEUERBACH, 2012, p. 26).

Este é o ponto nevrálgico que costura o tecido da crítica feuerbachiana ao longo do texto, sua tese magna: o exame radical da noção de Absoluto ou absolutidade, não apenas na filosofia de Hegel, mas no substrato em que se perfila no interior do moderno idealismo alemão e mesmo no cerne da filosofia enquanto atividade abstrata. Dirige este julgamento crítico, todavia, com árido grau de complexidade, envolvendo diversas facetas, algumas a seguir listadas e relacionadas ao problema de fundo, afinal, quiçá seja impossível proceder de outro modo quando se tem diante de si o arcabouço filosófico mais avançado já produzido até aquele período: "a filosofia de Hegel é, de fato, o sistema mais consumado que alguma vez apareceu" (FEUERBACH, 2012 , p. 30).

O problema é assim enunciado, tomado a pretexto do livro de Bayrhoffer:

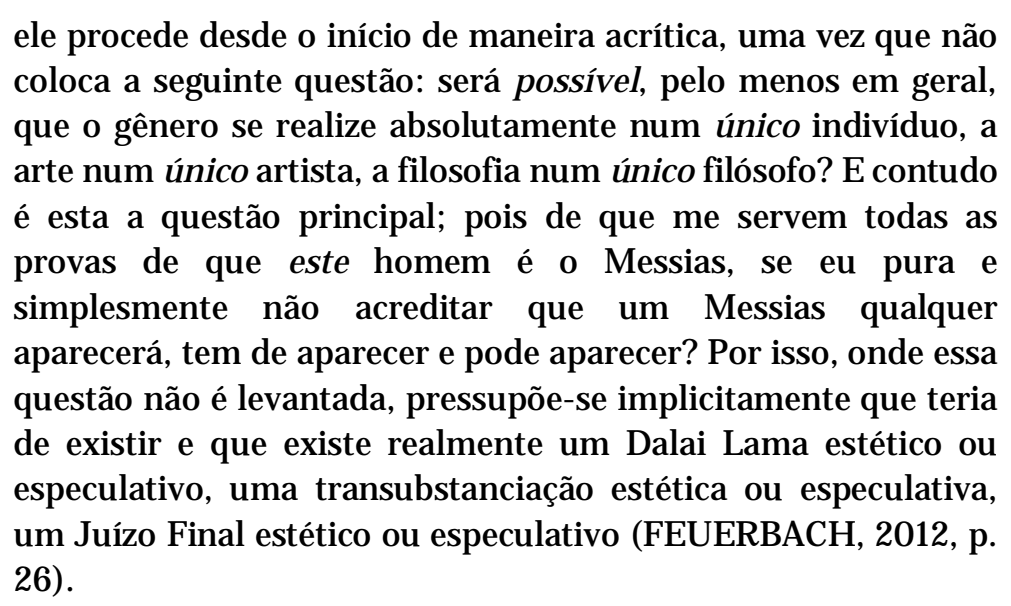

As mediações que se vinculam ao problema enfrentado por Feuerbach em seu texto são:

1. A concepção de que a filosofia de Hegel é uma filosofia determinada;

por mais que a filosofia de Hegel se distinga de todas as filosofias precedentes pela sua rigorosa cientificidade, pela sua universalidade e pela sua inegável riqueza de pensamento, ela é efetivamente uma filosofia determinada, particular (FEUERBACH, 2012, p. 28). 
2. A ideia de Absoluto como uma "abstração irreal", um absurdo, pois, tal qual o sobrenatural, a absolutidade pressupõe a indeterminação, o estar acima das limitações de tempo e espaço. Nota Feuerbach que este fundamento guarda vínculo com a teológica teoria da encarnação e da parúsia do cristianismo primitivo, na qual encarnação e história são mutuamente excludentes;

O que um dia entra no espaço e no tempo tem também de se submeter às leis do espaço e do tempo. À entrada no mundo, como um guarda, encontra-se o deus terminus [Deus limite]. A condição para entrar é a autolimitação. Seja o que for que se torne real só se torna real como algo determinado. (...) a crença dos Apóstolos e dos primeiros cristãos num iminente fim do mundo se encontrava intimamente associada à sua crença na encarnação. Com a manifestação da divindade num tempo e numa figura determinados suprimiu-se já em si o tempo, e mesmo o espaço, e por isso também nada mais se pode esperar a não ser o efetivo fim do mundo. Já não se pode pensar a história - ela é desprovida de finalidade e de sentido; encarnação e história são absolutamente incompatíveis; onde a divindade entra na história, suprime-se a história. Mas se apesar de tudo a história prossegue seu curso como antes, então a teoria da encarnação é refutada de fato pela própria história (FEUERBACH, 2012, pp. 26-7).

3. Sob a égide do primeiro enunciado (sobre a particularidade e determinidade da filosofia hegeliana), parte-se para sua demonstração mediante a análise imanente e genealógica ("genético-crítica", como grafada no texto) da filosofia do velho mestre.

Feuerbach demonstra que o começo proposto por Hegel na Ciência da lógica (começar pela noção de começo), calcado no aparente esvaziamento de pressupostos - porquanto se inicia com o conceito de ser, o ser puro, indeterminado, e não qualquer ser particular - reflete uma adesão a um esquema delineado na própria filosofia, particularmente na filosofia anterior, a de Fichte, na Doutrina da ciência ${ }^{8}$, de um lado, e a de Schelling, de outro, no Sistema do idealismo transcendental. Quanto ao "fundamento do começo da Lógica" (FEUERBACH, 2012, p. 38), diz Feuerbach:

Hegel é, neste aspecto, muito mais consequente, mais científico do que Fichte com o seu $\mathrm{Eu}=\mathrm{Eu}$. Mas sendo o começo o indeterminado, a progressão significa determinação. É apenas no decurso da exposição que se determina e se revela o que é

\footnotetext{
8 Para Fichte, a doutrina da ciência consiste na ciência da ciência em geral, que descobre e demarca o "princípio absolutamente primeiro e único que comanda pura e simplesmente o saber humano" (FICHTE, 1980, p. 23). Trata-se de um princípio axiomático, não suscetível de prova, indemonstrável, certo de si, o fundamento de toda certeza e todo saber, que se põe a si mesmo; este princípio seria a proposição: eu sou eu.
} 
isso com o qual eu começo. A progressão é, pois, uma regressão - eu regresso de novo àquilo de que parti - e ao retroceder volto a revogar a sucessão, a temporalização do pensamento: restabeleço a unidade perdida (FEUERBACH, 2012, p. 31).

Ora, tal "temporalização do pensamento" significa determinar-se no múltiplo e diverso mundo de entes, alienar-se como natureza e como história, processo que no fim, contudo, precisa ser revogado em favor da "unidade perdida". Também Marx aponta como este tratamento hegeliano da objetividade representa algo "escandaloso" (MARX, 2015, p. 378) na exteriorização do pensamento, isto é, macular-se na terrenalidade, movimento que no sucedâneo precisa ser acrisolado e purificado, esboroando as próprias determinações do ser ${ }^{9}$. Ademais, se o fundamento hegeliano é, de saída, uma contradição nos termos, visto que alça a identidade absoluta ou o ser puro indeterminado como pressuposto genético do ser, enquanto pensamento elevado ao nível mais radical de abstração pelo qual se deveria apreender o começo da investigação lógicofilosófica (o conceito de ser), Feuerbach, em uma tenaz recusa antiespeculativa, inverte os termos da álgebra hegeliana e inquire com argúcia ontológica:

por que constituir em geral um tal começo? Será que o conceito de começo já não é um objeto da crítica, será ele imediatamente verdadeiro e universal? Por que é que, no começo, não hei-de poder prescindir justamente do conceito de começo, por que não hei-de poder referir-me ao imediatamente real? Hegel começa com o ser, ou seja, com o conceito de ser; por que não hei-de poder começar com o próprio ser, ou seja, com o ser real? (FEUERBACH, 2012, p. 29).

Da conclusão da Lógica, Feuerbach aduz que "O pensar é uma atividade imediata na medida em que é atividade própria" (FEUERBACH, 2012, p. 32). Com ela, contra Fichte, busca demonstrar que "Os modos da demonstração e do raciocínio não são, pois, formas da razão em si, não são formas no interior de pensar e conhecer; são apenas formas de comunicação, modos de expressão, apresentações e representações, manifestações do pensamento" (FEUERBACH, 2012, p. 35). Contra uma autossuficiência e restrição a si da fórmula fichtiana, Feuerbach parece interpor o impulso originário e a vinculação ao outro (a mediação do Eu e do Tu), em que "a exposição do pensamento tem como seu fim último o ato cognoscitivo do outro" (FEUERBACH, 2012, p. 37) ${ }^{10}$. Desta forma, “A

9 “Ir além das determinações concretas é um evolver [Entwicklen] do pensar a partir de si mesmo" (HEGEL, s/d, p. 82).

10 Neste ponto, é razoável notar que, apesar do timão crítico feuerbachiano, sua base é ainda essencialmente de tipo gnosiologizante, pois as formas da demonstração e do raciocínio - que em Hegel se encontram sob a forma do silogismo lógico - , enquanto "meio homogêneo de pensamento" (LUKÁCS, 2012, p. 221) em face da heterogeneidade do real, têm sua gênese na práxis e são seu reflexo, ou seja, são algo mais do que 
demonstração é portanto unicamente o meio pelo qual retiro aos meus pensamentos a forma do que é meu, a fim de que o outro os reconheça como os seus próprios" (FEUERBACH, 2012, p. 36). Com isso, identifica também o limite formalista em que deságua a filosofia hegeliana em sua herança sistemática"1, pois, por mais que nele "O pensar sistemático não seja todavia o pensar em si, o pensar essencial, mas apenas o pensar que se expõe" (FEUERBACH, 2012, p. 30), "A exposição faz assim constantemente apelo a uma instância mais elevada em relação a ela, a uma instância apriorística. Ou não será isso que se passa com o 'ser' da Lógica de Hegel?” (FEUERBACH, 2012, p. 39). Ora, o que Feuerbach faz é apanhar a contradição insolúvel entre o circuito sistemático logicista que hipostasia o ser e a riqueza ontológica das determinações em sua processualidade dialética (da percepção deste segundo traço vem a assertiva, ainda no início do texto de Feuerbach, de que a característica peculiar da filosofia de Hegel, contra a cantilena salomônica da mesmidade, é a diferença) ${ }^{12}$.

Essa contradição no interior da filosofia de Hegel tem direta relação com o seu pressuposto acrítico - o Absoluto como resultado, como demonstração - que marca a identidade sujeito-objeto, espírito-natureza, repetindo a contradição fichtiana entre o Eu puro e o eu empírico (FEUERBACH, 2012, p. 40). A nosso ver, duas consequências são ressaltadas desta contradição fundante:

a) A falsidade e irrealidade do começo, o ser puro em sua unidade com o nada, revelam a verdade posta empiricamente pelo real, ou seja, "só o ser determinado é ser" [Nur bestimmtes Sein ist Sein], "todo o ser é ser determinado", "no conceito de ser reside o conceito de determinidade absoluta”. Assim,

Como pode então a Lógica, como pode em geral uma filosofia determinada, demonstrar a sua verdade e realidade, se começar com uma contradição em relação à realidade sensível, em relação ao entendimento da realidade, e não resolver essa contradição? (FEUERBACH, 2012, p. 41).

"manifestações do pensamento". A este respeito, esclarece Lukács: "Não é a forma do silogismo que se 'realiza' na práxis, mas são os elementos formais universalíssimos contidos em todo ato prático que se condensam na prática do pensamento humano de forma cada vez mais abstrata, até que, 'em virtude desses bilhões de repetições', adquirem a solidez de um axioma." (LUKÁCS, 2012, p. 220) Entendemos, todavia, que o próprio Feuerbach avança sobre o tema numa direção ontológica quando, em 1843, na Filosofia do futuro, afirma: "As leis da realidade são também leis do pensamento"; e continua: "Na realidade efetiva, os contrários estão sempre conexos apenas mediante um termo médio. Este termo médio é o objeto, o sujeito dos contrários." (FEUERBACH, 1988, p. 90)

${ }_{11}$ “Com efeito, sistema é apenas um círculo fechado em si, que não prossegue em linha reta ao infinito, mas que no fim retorna ao seu começo." (FEUERBACH, 2012, p. 30)

12 Cf. o rigoroso estudo de Lukács, "A falsa e a autêntica ontologia de Hegel” (in: LUKÁCS, 2012), bem como o valioso Feuerbach de Engels, já mencionado. 
b) A identidade sujeito-objeto traz consigo o primado do tempo em detrimento do espaço, o que significa, primeiramente, subsumir a autonomia e totalidade da natureza (do ser, da matéria) à atividade histórico-social humana (por conseguinte, suspender sua autonomia) e, em seguida, subsumir o próprio desenvolvimento histórico em seus diferentes graus no seio do Absoluto, convertendo esse desenvolvimento em simples predicado, momento da absolutidade. Assim, o ser sensível é tornado uma exteriorização e predicado do Espírito, da Ideia, posição que configura uma "concepção anti-histórica da natureza” (ENGELS, s/d, p. 183), algo que contrasta justo com o brilhantismo e pioneirismo de Hegel, que lançou luzes sobre a historicidade do mundo humano-social (LUKÁCS, 2012, p. 207). Diante do rebaixamento hegeliano da natureza, é possível entender como se explica a guinada materialista de Feuerbach e sua exaltação da natureza, sob o influxo das descobertas e avanços das ciências naturais até aquele período, o que representou a força e a potência do seu pensamento, ao lado de sua importante crítica da alienação religiosa e do estabelecimento do princípio da relação "homem a homem" como fundamento da sociedade. Igualmente, representou o beco sem saída em que desembocaram tanto sua filosofia da natureza quanto sua concepção liberal de sociedade, algo que será ressaltado neste trabalho no tocante à sua diferença específica com relação a Marx.

\subsection{Sinnlichkeit e objetivação genérica na mediação Eu-Tu}

Evidenciou-se o teor da crítica antiespeculativa feuerbachiana como reclamo do princípio da imanência, que se colige em torno da categoria do ser enquanto sensível, enquanto Sinnlichkeit (sensorialidade, sensibilidade), enquanto datidade exterior ao pensamento. Este fulcro de "realização-negação da filosofia especulativa" (AQUINO, 2014, p. 256), como impostação anunciada na agenda inadiável da nova filosofia ${ }^{13}$, reaparecerá com notável força nos escritos seguintes, que vão até 1843. As Teses provisórias para a reforma da filosofia (1842) assinalam, nesta direção, que:

A filosofia hegeliana é a supressão da contradição do pensamento e do ser, como a exprimiu particularmente Kant, mas, cuidado!, é apenas a supressão desta contradição no interior da contradição - no interior de um só e mesmo elemento - no seio do pensamento. Em Hegel, o pensamento é o ser; - o pensamento é o sujeito, o ser é o predicado. A lógica é o pensamento num elemento do pensamento, ou pensamento

${ }^{13}$ Cf. Necessidade de uma reforma da filosofia (1842), texto que se apresenta mediante o desígnio das exigências de uma "nova época", carecimento que não se satisfaz com as respostas dadas pela velha filosofia (panteísmo, empirismo, idealismo transcendental e filosofia especulativa), criticamente avaliadas em Princípios da filosofia do futuro. 
que a si mesmo se pensa - o pensamento como sujeito sem predicado ou o pensamento que é simultaneamente sujeito e o seu próprio predicado. (...) Este pensamento realizado e alienado é a natureza, o real em geral, o ser. Mas, qual é o verdadeiro real neste real? É o pensamento - que bem depressa se despoja do predicado da realidade para, de novo, estabelecer a sua falta de predicados como sua essência verdadeira. Mas, justamente por isso, Hegel não chegou ao ser como ser, ao ser livre, independente, feliz em si mesmo. Hegel pensou unicamente os objetos como predicados do pensamento que a si mesmo se pensa. (...) A doutrina hegeliana de que a natureza é a realidade posta pela Ideia é apenas a expressão racional da doutrina teológica, segundo a qual a natureza é criada por Deus, o ser material por um Ser imaterial, isto é, um ser abstrato (FEUERBACH, 1988, pp. 30-1).

Conforme já exposto, é da crítica à plataforma hegeliana da identidade espírito-natureza ${ }^{14}$ que Feuerbach vai deslindar a asserção de uma percuciente objetividade materialista do ser, que naquelas Teses se apresenta em passagens cruciais, tal como se pode ler numa das mais exemplares:

\begin{abstract}
A verdadeira relação entre pensamento e ser é apenas esta: o ser é o sujeito, o pensamento, o predicado. O pensamento provém do ser, mas não o ser do pensamento. O ser existe a partir de si e por si - o ser é só dado pelo ser. O ser tem o seu fundamento em si mesmo, porque só o ser é sentido, razão, necessidade, verdade, numa palavra, tudo em todas as coisas. - O ser é, porque o não ser é não ser, isto é, nada, não-sentido. (FEUERBACH, 1988, p. 31)
\end{abstract}

Podemos afirmar que desde a ontologia de Parmênides, que postulava a unitária realidade do ser enquanto pensar, pois o existir equivalia a não-ser, até a tentativa de solução por Hegel das antinomias entre o idealismo subjetivo de Kant e Fichte e a filosofia da natureza de Schelling, Feuerbach coloca a descoberto "novas premências ontológicas" (CHASIN, 2009, p. 42), isto é, da legalidade própria e autônoma da matéria, do ser objetivo e sensível, da natureza, em relação à consciência e à subjetividade, e que não existe nem dispõe de realidade qualquer coisa que não seja matéria e sensibilidade, colocando, desse modo, a noção da imaterialidade ou não-materialidade como uma absurdidade, algo que só pode ser pensado no plano da mais irreal abstração.

Já n'A essência do cristianismo se anota que "o objeto sensorial está fora do homem", "o objeto sensorial é em si um objeto indiferente,

14 'Na natureza, nenhum outro se conhece a não ser a Ideia, mas esta na forma da exteriorização; no espírito, é igualmente a mesma enquanto é para si, e em si e para si devém." (HEGEL, s/d, § 18) Noutra passagem, se diz: "Assim se afirma, pois, imediatamente que a ideia só é mediante o ser e, inversamente, o ser só mediante a ideia, é o verdadeiro." (HEGEL, s/d, § 70) 
independente da intenção, do juízo" (FEUERBACH, 1989a, p. 55), ou ainda que "o mundo em geral existe fora da minha ideia, fora de mim mesmo, um ser diverso da subjetividade" (FEUERBACH, 1989a, p. 150). E nas Teses provisórias diz: “Um ser sem afecção é um ser sem ser. Mas um ser sem afecção nada mais é do que um ser sem sensibilidade, sem matéria." (FEUERBACH, 1988, p. 27)

É, pois, algo diáfano o que se extrai destas diversas asseverações de Feuerbach: um materialismo imanentista pautado no ser objetivo e sensível e, sob ele, uma chave para a compreensão da subjetividade, pois "o pensamento provém do ser, mas não o ser do pensamento".

Quando, em 1859, Marx afirma, numa passagem que se tornaria emblemática: "Não é a consciência dos homens que determina o seu ser, mas, ao contrário, é o seu ser social que determina a sua consciência" (MARX, 1991, p. 30), não se pode olvidar a indelével presença de Feuerbach, a despeito de o conteúdo e a compreensão do primeiro nesta assertiva ir mais além do que coube às intuições e descobertas do segundo.

Destarte, é prudente indagar: qual a essência do ser segundo Feuerbach? "A essência do ser enquanto ser é a essência da natureza." (FEUERBACH, 1988, p. 32) O estatuto do ser material, a natureza enquanto fundamento de si mesma, é rastreado a partir de suas próprias determinações legais, isto é, a relação de causalidade e o par espaço-tempo como suas qualidades imanentes, pois "O espaço e o tempo são as formas de existência de todo o ser. Só a existência no espaço e no tempo é existência" (FEUERBACH, 1988, p. 26).

Assim, em termos sistemáticos, podemos dizer que a natureza, para Feuerbach: a) constitui uma verdade dada aos sentidos, que existe independentemente da consciência humana e que também não é resultado do arbítrio de um deus fictício; b) compreende a matéria como incriada, eterna, causa sui; c) é necessária, regida por legalidade própria; d) é correspondente apenas a si mesma (CHAGAS, 2009).

Se temos, de um lado, o primado da natureza, do outro, o modo de ser pertencente ao homem é aquele objetivado enquanto essência-gênero, que só se realiza, no entanto, como alteridade, pela mediação do outro. Trata-se de uma filosofia com desiderato no reconhecimento de uma objetividade relacional, traduzida na noção de que o ser de um ente é posto e objetivado não por si mesmo, como na autossuficiente fórmula fichtiana, mas pelo outro ser a ele exterior. A sua essência está fora de si, está no outro, cujo carecimento e necessidade permitem fazer dele seu objeto e sua afirmação objetiva.

A esse respeito, sentencia Aquino:

é o sensível enquanto condição humano-genérica, posta como relação padecente do homem com o outro homem e, por meio deste, com os objetos sensíveis que lhes estão opostos. Se um 
objeto somente me é acessível mediante o outro homem, assim o é porque, enquanto objeto, se constitui de uma objetivação humano-genérica no estrito sentido de uma objetivação na e da relação Eu-Tu (AQUINO, 2014, p. 261).

Neste passo, elucida Adriana Serrão:

Em termos ontológicos, existência equivale a coexistência; todo ser é ser em relação, simultaneamente ativo e receptivo, sujeito e objeto. Em termos antropológicos, o homem é ser incarnado (um corpo-sujeito), no mundo e com os outros, na relação recíproca de Eu e Tu: "Eu sou eu - para mim - e ao mesmo tempo tu - para o outro". (SERRÃO, 2015, p. 51)

Anos mais tarde, nas Preleções sobre a essência da religião (1851), Feuerbach sintetiza o conjunto de suas preocupações, remetendo exatamente a esta articulação bilateral:

Minha doutrina ou ponto de vista se resume então em duas palavras: natureza e homem. O ser que para mim pressupõe o homem, o ser que é a causa ou o fundamento do homem, a quem ele deve seu aparecimento e existência, não é para mim Deus - uma palavra mística, indefinida e ambígua - mas a natureza - uma coisa e uma palavra clara, sensível, indubitável. Mas o ser no qual a natureza se torna um ser pessoal, consciente e inteligente é para mim o homem. (FEUERBACH, 1989b, p. 27)

\section{3 - Ontologia e objetividade em Marx}

Um ser não objetivo é um não-ser. Karl Marx

O primeiro pressuposto ontológico de Marx, nos termos da postulação de uma ontologia geral como substrato de uma ontologia do ser social, qual indicado ainda na introdução, foi enunciado numa formulação singular nos Manuscritos econômico-filosóficos de 1844, período em que ele, radicado em Paris, transitava da fase pré-marxiana para o talhe propriamente marxiano que enforma sua investigação ${ }^{15}$. Aí, ele sentencia: “Um ser não objetivo é um não-ser" (MARX, 2015, p. 376). A afirmação de Marx coloca, numa franca retomada de Feuerbach, uma posição que reconhece a objetividade como lastro de todos os seres, processos e relações, isto é, que existe um mundo de seres autônoma e independentemente da subjetividade, da especulação, da consciência; e sem a qual o mundo objetivo produzido pela atividade sensível humana não pode ser compreendido nas determinações que o configuram como tal.

15 Sobre a caracterização do período de gênese do caráter específico na direção da maturidade da reflexão de Marx, cf. Chasin (2009). 
No Caderno III dos Manuscritos - o excerto "Crítica da dialética e filosofia de Hegel em geral" - está presente claro tributo pago por Marx a Feuerbach, no seu avanço fundamental à crítica hegeliana, distanciando-o "de todas estas condutas frívolas do idealismo que expira sob a forma de crítica (o jovem hegelianismo)” (MARX, 2015, p. 362). Diz Marx:

Feuerbach é o único que tem uma relação crítica, séria, com a dialética de Hegel e que fez verdadeiras descobertas nesse domínio, é em geral o verdadeiro superador [Überwinder] da velha filosofia. A grandeza da obra e a simplicidade sem alarde com que F[euerbach] a dá ao mundo estão em um espantoso contraste com a atitude inversa. (MARX, 2015, p. 363)

A filosofia de Feuerbach avançou em três frentes: a) mediante a crítica da filosofia enquanto pensamento religioso sob invólucro especulativo-racional, sendo vista como "uma outra forma e modo de existência da alienação da essência humana" (MARX, 2015, p. 363); b) ao fundar uma autêntica teoria materialista cuja base seria a relação do "homem ao homem"; c) ao opor o positivo Absoluto (negação da negação) a um princípio positivamente fundado em si mesmo (o ser material, a natureza).

Ainda este excerto dos Manuscritos tenciona decididamente demonstrar, contra "todas as ilusões da especulação" (MARX, 2015, p. 379), o caráter objetivo de todo ser, tanto da natureza, por seu garante ineliminável como primária objetividade, quanto do ser social enquanto desenvolvimento complexo desta objetividade. Este ocorre, porém, com uma regência própria, específica, refutando de conjunto o pressuposto idealista da consciência como matriz da materialidade ("que põe a coisidade" [MARX, 2015, p. 373], o objeto) ou como pertencente em sinal de identidade a ela mesma. "O ser objetivo opera objetivamente, e não operaria objetivamente se o objetivo não residisse na sua determinação essencial. Ele só cria, põe objetos, porque é posto por objetos, porque é, à partida [von Haus aus] natureza" (MARX, 2015, p. 375).

[O homem] em parte, œmo ser natural, corpóreo, sensível, objetivo, ele é um ser que sofre, condicionado e limitado, tal como o são o animal e a planta; i. e, os objetos dos seus impulsos existem fora dele, como objetos independentes dele; mas esses objetos são objetos da sua necessidade, objetos essenciais, indispensáveis para a ação e confirmação das suas forças essenciais. (...) Ser objetivo, natural, sensível e do mesmo modo ter objeto, natureza, sentido fora de si ou ser propriamente objeto, natureza, sentido para um terceiro, é idêntico. A fome é uma necessidade natural; precisa, por isso, de uma natureza fora de si, de um objeto fora de si, para se satisfazer, para se saciar. A fome é a necessidade confessada do meu corpo de um objeto que lhe é exterior, indispensável à sua integridade e exteriorização da sua essência. O Sol é o objeto da planta, um objeto que lhe é indispensável, que lhe confirma a 
vida, tal como a planta é objeto do Sol, como exteriorização da força despertadora de vida do Sol, da força essencial objetiva do Sol (MARX, 2015, pp. 375-6).

Fica faceado que "O homem é imediatamente ser da natureza" (MARX, 2015, p. 375) e, tal como os outros seres, sua condição corpórea, sensível, participa primariamente da sua objetividade. Ou seja, os objetos de suas necessidades existem fora dele como objetos independentes, indispensáveis, no entanto, à exteriorização de sua própria existência. Concepção até aí fiel a Feuerbach, que, nos Princípios da filosofia do futuro, já dissera: "só um ser sensível precisa de outras coisas fora dele para a sua existência" (FEUERBACH, 1988, p. 41). Essa dimensão do carecimento dos seres é sinônimo de padecimento, sofrimento, por ter seu ser fora de si. "Ser sensível é ser que sofre" (MARX, 2015, p. 376), pois "um ser sem afeç̧ão é um ser sem ser" (FEUERBACH, 1988, p. 27).

O que é um ser objetivo? É o ser que tem fora de si um objeto sensível pelo qual sua qualidade pode pôr-se, sua essencialidade pode exteriorizar-se, tanto quanto este ser-outro. Portanto, não somente padecimento conforma o ser, mas atividade que o impele intensamente ao objeto do seu carecimento "para se satisfazer, para se saciar". A objetividade do ser se perfaz relacionalmente, qual Feuerbach já havia sentenciado:

\begin{abstract}
Mas o que um ser é só se conhece a partir do seu objeto; o objeto a que se refere um ser nada mais é do que a sua essência revelada. Assim, o objeto dos animais vegetarianos é a planta; é por este objeto que eles se distinguem essencialmente dos outros animais, os carnívoros. Assim, o objeto do olho é a luz, não o som, nem o odor. É porém no objeto do olho que se torna manifesta a sua essência. É, pois, a mesma coisa não ver ou não ter olhos. Por conseguinte, também na vida designamos as coisas e os seres apenas segundo os seus objetos. O olho é o "órgão da luz". O que trabalha a terra é um camponês; quem tem a caça como objeto da sua atividade é um caçador; quem apanha peixes é um pescador, e assim por diante. (FEUERBACH, 1988, p. 42)
\end{abstract}

A relevância nuclear deste arcabouço em torno do ser objetivo, de um materialismo monista, radical e unitário, que, entrementes, não negligencia a captura adequada da forma como se põe a objetividade própria ao ser social, foi constatada na fala do maduro Lukács, quando de sua autocrítica em conhecido "Prefácio de 1967" a História e consciência de classe, no qual se referiu justamente a este traço dos Manuscritos de 1844:

De qualquer modo, ainda consigo me lembrar do efeito transformador que produziu em mim as palavras de Marx sobre a objetificação como propriedade material primária de todas as coisas e de todas as relações. A isso se somava a compreensão, 
já mencionada, de que a objetificação é um tipo natural positivo ou negativo, conforme o caso - de domínio humano sobre o mundo, ao passo que a alienação representa uma variante especial que se realiza sob determinadas circunstâncias sociais. (LUKÁCS, 2003, p. 46)

Ora, quando as exigências de investigação acerca do "domínio humano sobre o mundo" se impõem em seu melhor fulgor materialista, isto é, quando as condições societárias alcançam seu amadurecimento sob o regime do capital, vemos então as consonâncias entre Feuerbach e Marx se debilitarem e entre eles se acentuar o distanciamento marcado pela crítica marxiana explícita que se enfeixa em posições de fato bastante distintas. Perceber as determinações específicas da sociabilidade capitalista, tomadas em perspectiva com o largo desenvolvimento histórico, ademais da sintonia com as descobertas das ciências naturais, permitem a Marx capturar os liames adequados da relação naturezasociedade, relação que, em Feuerbach, mostra-se bastante problemática. É razoável, desta forma, assinalar alguns aspectos da cisão entre ambos.

\subsection{Feuerbach e Marx: a differentia specifica}

Alinhamo-nos a Garcia na percepção de que os enunciados ontológicos e o materialismo prospectados por Feuerbach esbarram em sisudos limites "em decorrência de sua falsa concepção ontológica de fundo", quando ele se torna "incapaz de apreender a gênese, formação e função sociais da consciência dos indivíduos" (GARCIA, 2011, p. 11). Este aspecto crucial, bem observado, está intimamente articulado aos demais elementos que cosem a differentia specifica entre os dois filósofos. Se não, vejamos.

A crítica decisiva da identidade sujeito-objeto e da identidade entre objetivação e alienação em Hegel, já endereçadas por Feuerbach, será a porta de entrada de Marx para uma impostação ontológica superior àquilo que restava deficiente tanto no materialismo de Feuerbach quanto no idealismo hegeliano.

Para Marx, o inteiro processo de desenvolvimento da Consciência no devir, na lógica-ontológica de Hegel (LUKÁCS, 2012), mediante oposições e negações em seu incessante movimento, tem sua súmula na contradição entre pensamento abstrato e realidade sensível (existência sensorial real). Daí, retiramos duas implicações de monta: a) a desumanização efetiva produzida pelo trabalho alienado é apenas concebida como "momento" da exteriorização/alienação da Consciência/Infinito/Ideia. A respeito desta inversão hegeliana, Marx afirma: "O que vigora como essência posta e a ser superada da alienação é não que a essência humana se objetive inumanamente, em oposição a si 
própria, mas, antes, que ela se objetive em diferença de e em oposição ao pensar abstrato" (MARX, 2015, pp. 367-8); b) este estreito limite da alienação assim apreendida, dado que tomada positivamente como objetivação posta pelo pensamento, produz uma intendição mais de fundo acerca do caráter ontológico da realidade, suprimida em favor de um idealismo que não tem um princípio positivamente fundado (o ser, a realidade material). O estatuto a que se converte o objeto é, no fundo, conforme argumenta Marx, negativo, uma nadidade [Nichtigkeit]. A primazia do saber como precípua atividade objetiva declara guerra contra a objetividade enquanto tal, chegando ao limite de sua abdução. Segundo Marx, em Hegel:

só o espírito é a verdadeira essência do homem, e a verdadeira forma do espírito é o espírito pensante, o espírito lógico, especulativo. A humanidade da natureza e da natureza gerada pela história, dos produtos do homem, aparece no fato de que são produtos do espírito abstrato e, nessa medida, portanto, momentos espirituais, seres de pensamento. (MARX, 2015, pp. 368-9)

Nota-se que a crítica de Marx a Hegel, diferentemente da de Feuerbach, retém aquilo que se mostra ativo na dialética hegeliana, a história enquanto autoprodução humana que remodela a natureza, no sentido de uma objetivação subjetivada que não é redutível simplesmente ao concurso das forças naturais, ou seja, "A humanidade da natureza e da natureza gerada pela história". Desta forma, ele articula uma posição ontológica nova, que apreende na relação entre objetividade e subjetividade "uma concepção do ser social dialeticamente unitária", no dizer de Lukács (2012, p. 29).

"O homem, porém, é não apenas ser da natureza, mas ser da natureza humano". Se é verdade que primariamente o homem participa da objetividade natural, dada a sua corporalidade e materialidade, como os demais seres, a unidade que envolve esse pertencimento não pode ser confundida com pura identidade. Observa Marx que "nem a natureza objetivamente - nem a natureza subjetivamente está imediatamente dada, de um modo adequado, ao ser humano" (MARX, 2015, p. 377). Dar aos objetos da natureza outra forma, adequada às necessidades sociais, uma forma humana, que n’O capital Marx chamará de metabolismo, uma alteração substantiva nas formas da matéria, consiste pari passu na elaboração de uma “objetividade humana”. Coube a Marx a grandiosidade da descoberta de que esta transitividade material entre natureza e sociedade reside no trabalho, na atividade vital, na vida produtiva. $\mathrm{O}$ homem ergue todo o tecido social mediado pela sua atividade vital a partir da base física da natureza. Ele humaniza a natureza, fazendo-a material em que imprime sua finalidade consciente pelo trabalho, criando uma 
progressiva riqueza humana, uma constelação de objetivações exteriores a ele, por isso mesmo "tanto mais universal é o domínio da natureza inorgânica de que ele vive" (MARX, 2015, p. 310). O ser humano produz-se a si mesmo no e pelo trabalho universalmente, como ser genérico, no qual a vida individual só pode constituir-se como tal enquanto vida genérica. Trata-se do ser para si mesmo, que participa com sua singularidade e como condição mesma para a própria singularidade, da universalidade da atividade humana, das objetivações pelas quais ele exterioriza sua subjetividade, a si mesmo. Universalidade não quer dizer imutabilidade do ser pairando no transcurso do tempo, e sim processualidade (a história) que marca a exteriorização de vida, pois a história é o ato de nascimento que se supera. Sobre isso, e em realce ao papel ontológico da atividade sensível do trabalho, escreveu Marx:

(...) só na elaboração do mundo objetivo o homem se prova realmente como ser genérico. Esta produção é a sua vida genérica operativa. Por ela, a natureza aparece como obra sua e sua realidade. O objeto do trabalho é, portanto, a objetivação da vida genérica do homem, na medida em que ele se duplica não só intelectualmente, como na consciência, mas também operativamente [werktätig], realmente, e contempla-se por isso num mundo criado por ele (MARX, 2015, p. 313).

No plano do ser material, sensível, é importante destacar como Feuerbach apanha a objetividade num plano estrito da senso-percepção, ou seja, num nível puramente empírico que acaba por comprometer enormemente a compreensão da objetividade social que, simultaneamente, estabelece uma unidade com a natureza que é de identidade e de não identidade. Em Feuerbach, o lastro da objetividade social é em larga medida redutível à natureza. "Contemplai a natureza, contemplai o homem!, pois ambos se confundem" (FEUERBACH, 1988, p. 32), afirma nas Teses provisórias. Chega mesmo a sentenciar que, diante da alienação vigente, "O retorno à Natureza é a única fonte de salvação" (FEUERBACH, 2012, p. 62).

Dizer que Feuerbach não faz distinção entre homem e natureza seria algo incorreto, além de injusto. Todavia, das determinações que ele apresenta nesta diferenciação, confirmam-se a concepção metafísica de natureza que possui e a compreensão bastante limitada, no sentido de um materialismo contemplativo, acerca da entificação social, em que pese seu avanço e contribuição para a definição de uma ontologia materialista do ser objetivo. Como já citado, o filósofo afirma: "o ser no qual a natureza se torna um ser pessoal, consciente e inteligente é para mim o homem" (FEUERBACH, 1989b, p. 27).

Vimos que Feuerbach se opõe eloquentemente à "onipotência da razão” especulativa, redimensionando a relação entre matéria e espírito, 
ser e consciência, objetividade e subjetividade, predicado e sujeito, ao arrolar a Sinnlichkeit como fundamento do ser objetivo. O que figura e é realçado, todavia, como distintivo no ser objetivo humano é o elemento da consciência e da inteligência. Ou seja, ele "no concibe la sensoriedad como una actividad sensorial humana práctica" (MARX, 2006, p. 58). Este ponto é, seguramente, o nó górdio donde brota a ambivalência de seu pensamento, na medida em que sua concepção de mediação frente à imediatidade de seres e relações é essencialmente subjetiva. Feuerbach empresta à consciência e à atividade genérica os atributos da universalidade, da totalidade, da infinitude, que, por seu turno, não pertenceriam à própria coisa e aos nexos objetivos entre seres humanos reais e empíricos.

Desta forma, a parte ativa do humano, seu engendramento efetivo, é apanhada apenas enquanto atividade da consciência, enquanto comportamento teórico, captando assim a vida prática e a atividade material "solo en su forma suciamente judaica de manifestarse" (MARX, 2006, p. 57), tal como diz Marx nas Teses Ad Feuerbach.

Feuerbach, mesmo com o imenso avanço materialista ontológico que promove, ainda se vê envolto na atmosfera da exaltação idealista da consciência, em detrimento da atividade prático-sensível e de seu caráter fundante das objetivações nas quais o homem exprime sua essencialidade. Por isso, a sua concepção de essência humana é pautada num dramático fetichismo, que coloca a tríade razão, amor e vontade como predicados imutáveis do humano, que ao mesmo tempo conformam a essência humana e são moldados por ela (FEUERBACH, 1989a, p. 45; RANIERI, 2006, p. 68). Para Marx, a essência humana se refere ao "conjunto de las relaciones sociales", a que se deve "entenderse racionalmente" como "actividad práctica", observando sua "base terrenal" e sua "trayectoria histórica” (MARX, 2006., p. 58).

Acompanhando Sampaio e Frederico (SAMPAIO; FREDERICO, 2006, p. 75), podemos dizer de Feuerbach, pois, que "a ambígua unidade imediata sujeito-objeto universal de sua gnosiologia humanista" encerra a chave problemática da interpretação de seu pensamento, que, não por acaso, incidiu e se desdobrou em posições radicalmente distintas e mesmo antagônicas, a exemplo do materialismo marxiano e da gnosiologia antimaterialista de Nietzsche.

O ponto de vista feuerbachiano acerca da essência humana se corrobora contemplativo quando verificamos o laço que este possui com o gênero humano [Gattungwesen], para ele assaz passivo e confirmado na afecção. A letra marxiana, em passagem já mencionada, assevera: "É exatamente na atuação sobre o mundo objetivo que o homem se manifesta como verdadeiro ser genérico. Esta produção é a sua vida genérica ativa”; 
enquanto isso, para Feuerbach, o plexo Eu-Tu, que pauta a relação genérica, tem por excelência um móvel padecente, "una generalidad interna, muda, que se limita a unir naturalmente los muchos individuos". Tratar-se-ia muito mais de uma visão que, "presuponiendo un individuo humano abstracto" (MARX, 2006, p. 58), tomaria o lado "prático", a mediação Eu-Tu, como atividade autônoma, autossuficiente e teórica, melhor traduzida pelo signo da comunicação e da linguagem (AQUINO, 2014 , p. 259).

Outro aspecto distintivo a ser notado é a concepção liberal de sociedade de Feuerbach. Apesar da fecundidade de sua nova teoria da alienação aplicada ao objeto religioso e filosófico, há uma resistência sua em estendê-la a outros objetos da socialidade, como o estado e a política, por exemplo, que, àquela época, agitavam as inquietações teóricas e práticas dos herdeiros críticos do hegelianismo. Marx e Engels buscam estimular Feuerbach a tomar parte nos debates públicos sobre a situação europeia e prussiana, ao passo que este mantém reserva. O próprio Marx lhe envia, junto à carta supracitada, a sua "Introdução" à Crítica da Filosofia do direito de Hegel, redigida em 1843, e não obtém devolutiva. Mas lá já sublinha Marx: “O homem é o mundo do homem, o estado, a sociedade. Este estado e esta sociedade produzem a religião, uma consciência invertida do mundo, porque eles são um mundo invertido" (MARX, 2010a, p. 145). E antes, em Sobre a questão judaica, assinalou: "Para nós, a religião não é mais a razão, mas apenas o fenômeno da limitação mundana." (MARX, 2010b, p. 38)

Este percurso e enriquecimento da teoria da alienação marxiana nos anos iniciais da década de 1840 - que vai da análise das formas de autoconsciência invertida até o rastreamento de suas raízes no "factum nacional-econômico, a alienação do trabalhador e da sua produção" (MARX, 2015, p. 314) - exprimiu-se numa concepção crítica de sociedade e estado bem mais avançada do que aquela propugnada por Feuerbach, para quem:

O homem é a essência fundamental do estado. O estado é a totalidade realizada, elaborada e explicitada da essência humana. No estado, as qualidades ou atividades essenciais do homem realizam-se em "estados" particulares; mas, na pessoa do chefe do estado, são reconduzidas à identidade. O chefe do estado deve representar todos os "estados"; diante dele, todos são igualmente necessários e igualmente justificados. O chefe do estado é o representante do homem universal. (FEUERBACH, 1988, p. 35) 


\section{4 - Considerações finais}

A aproximação que realizamos entre Feuerbach e Marx buscou salientar os aspectos de consonância entre ambos, a virada ontológica decisiva que o pensamento do primeiro anuncia e a retenção por Marx de um pressuposto grandioso apresentado pelo primeiro. Evidentemente, isto não bastou para fazer da ontologia do ser objetivo de Marx idêntica à de Feuerbach.

Resta demonstrado que Feuerbach elabora uma instigante crítica filosófica pautada num mirante ontológico, ao resgatar um potente materialismo objetivo e ao abrir uma via para uma igual compreensão materialista da subjetividade. Sua crítica ao sujeito-objeto idêntico hegeliano não chega, no entanto, às suas últimas consequências, de modo que esta debilidade permanece no âmbito de sua leitura do mundo humano e do papel desempenhado pela subjetividade na objetivação e cognição da realidade.

Estas antinomias na filosofia feuerbachiana se expressam nos limites de sua compreensão da objetividade sócio-histórica e das saídas apontadas para além da alienação, a saber, pautadas num liberalismo político acrítico e numa solução moral baseada no "Autodomínio racional em relação a si mesmo, e amor - sempre o amor! - em nossas relações com os outros" (ENGELS, s/d, p. 190).

Recorrendo uma vez mais à síntese lukacsiana, observa-se que:

O juízo de Marx sobre Feuerbach, portanto, tem sempre dois lados: o reconhecimento de sua virada ontológica como o único ato filosófico sério desse período e, ao mesmo tempo, a constatação de seu limite, ou seja, do fato de que o materialismo alemão feuerbachiano nem mesmo se deu conta do problema da ontologia do ser social. Externa-se aí não só a lucidez e a universalidade filosóficas de Marx; essa tomada de posição também lança luz sobre seu desenvolvimento inicial, sobre o posto central que nele assumiram os problemas ontológicos do ser social (LUKÁCS, 2012, p. 283).

É mister ter tais considerações em vista para uma avaliação adequada que ressalte e restitua a grandiosidade do feito de cada um destes filósofos, que abriram, enfim, uma nova etapa na história da ontologia enquanto problema humano, importando-nos em especial o processo de emergência do tertium datur marxiano.

\section{Referências bibliográficas}

ALVES, Antônio J osé Lopes. Marx e a analítica do capital: uma teoria das Daseinsformen. Saarbrücken, Alemanha: Novas Edições Acadêmicas OmniScriptum GmbH \& Co. KG, 2013. 
AQUINO, J oão Emiliano Fortaleza de. Feuerbach e a fundação sensível da filosofia: imediatidade e mediação na relação eu-tu. Kriterion, Belo Horizonte, n. 129, pp. 247-263, jun. 2014.

CHAGAS, Eduardo F. A majestade da natureza em Ludwig Feuerbach. In: ; REDYSON, D.; PAULA, M. G. de (Orgs). Homem e natureza em Ludwig Feuerbach. Fortaleza: Edições UFC, 2009, pp. 37-65.

; REDYSON, Deyve. "Apresentação”. In: FEUERBACH, Ludwig. Para a crítica da filosofia de Hegel. Trad. Adriana Veríssimo Serrão. São Paulo: LiberArs, 2012.

CHASIN, J osé. Marx: estatuto ontológico e resolução metodológica. São Paulo: Boitempo, 2009.

ENGELS, F. "Ludwig Feuerbach e o fim da filosofia clássica alemã”. In: MARX, Karl; . Obras escolhidas v. III. São Paulo: Alfa-Ômega, s/d.

FERNANDES, Florestan (Org.). Marx \& Engels. Col. Grandes Cientistas Sociais. 3. ed. São Paulo: Ática, 1989.

FEUERBACH, Ludwig. Princípios da filosofia do futuro e outros escritos. Trad. Artur Morão. Lisboa: Edições 70, 1988.

. A essência do cristianismo. Campinas: Papirus, 1989a.

$1989 \mathrm{~b}$.

. Preleções sobre a essência da religião. Campinas: Papirus,

. Para a crítica da filosofia de Hegel. Trad. Adriana Veríssimo Serrão. São Paulo: LiberArs, 2012.

FICHTE, J ohann G. Sobre o conceito da doutrina-da-ciência ou da assim chamada filosofia. São Paulo: Abril, 1980.

GARCIA, Marlon. A crítica de G. Lukács a L. Feuerbach em Para uma ontologia do ser social. Colóquio Nacional Marx e o Marxismo: teoria e prática, Rio de J aneiro, 2011.

GÍL MARTÍNEZ, J oaquín. Recepción y crítica del pensamiento filosófico de Ludwig Feuerbach. Kriterion, Belo Horizonte, n. 134, pp. 505-24, ago. 2016.

GRESPAN, J orge. A dialética do avesso. Crítica Marxista, São Paulo, v. 14, pp. 26-47, 2002.

HEGEL, Georg. Enciclopédia das ciências filosóficas em epítome v. I (ciência da lógica). Lisboa: Edições 70, s/ d.

LUKÁCS, György. História e consciência de classe: estudos sobre a dialética marxista. São Paulo: Martins Fontes, 2003.

2012 .

. Para uma ontologia do ser social v. I. São Paulo: Boitempo,

MARX, Karl. Carta de Carlos Marx a Ludwig Feuerbach [11 ago. 1844]. In: - Cuadernos de Paris: notas de lectura de 1844. México: Ediciones Era, 1974. 
1991.

. Para a crítica da economia política. São Paulo: Nova Cultural, . “Tesis sobre Feuerbach”. In: ENGELS, Federico; MARX, Carlos. Ludwig Feuerbach y el fin de la filosofía clásica alemana y otros escritos sobre Feuerbach. Madri: Fundación Federico Engels, 2006.

2010a.

. Crítica da filosofia do direito de Hegel. São Paulo: Boitempo, . Sobre a questão judaica. São Paulo: Boitempo, $2010 b$.

2011

. Grundrisse. São Paulo/Rio de J aneiro: Boitempo/Ed. UFRJ, . Cadernos de Paris e Manuscritos econômico-filosóficos de 1844. São Paulo: Expressão Popular, 2015.

RANIERI, J esus. Da produção do chamado "jovem Marx": algumas notas sobre os Manuscritos econômico-filosóficos. Outubro, São Paulo, v. 14, pp. 63-80, 2006.

SAMPAIO, Benedicto Arthur; FREDERICO, Celso. Dialética e materialismo: Marx entre Hegel e Feuerbach. Rio de J aneiro: Ed. UFRJ, 2006.

SERRÃO, Adriana Veríssimo. Ser e agir para uma articulação entre antropologia e ética em Ludwig Feuerbach. Revista Dialectus, ano 2, n. 6, pp. 47-59, jan.-ago. 2015.

Como citar:

BEZERRA, Vinícius Pereira. Ontologia e objetividade em Feuerbach e Marx. Verinotio - Revista on-line de Filosofia e Ciências Humanas, Rio das Ostras, v. 24, n. 2, pp. 76-99, nov. 2018.

Data de envio: 9 jul. 2017

Data de aceite: 17 jan. 2018 